\title{
Retinal proteomic evaluation of rats following streptozotocin-injection using shotgun proteomics
}

\author{
HIROKO OTAKE* , TETUSHI YAMAMOTO*, SAORI DEGUCHI, ATUSHI TAGA and NORIAKI NAGAI \\ Faculty of Pharmacy, Kindai University, Higashi-Osaka, Osaka 577-8502, Japan
}

Received June 12, 2019; Accepted September 24, 2019

DOI: $10.3892 / \mathrm{mmr} .2019 .10801$

\begin{abstract}
It is important to elucidate how retinal stimulation leads to retinal protection and dysfunction. The current study aimed to identify factors that are up- and downregulated in the retinas of streptozotocin (STZ)-induced diabetic rats with acute retinal dysfunction. Retinal function was measured and changes in protein expressions were determined using electroretinograms (ERGs) and liquid chromatography/mass spectroscopy-based shotgun proteomics, respectively. The results revealed that the plasma glucose levels of STZ rats were markedly higher when compared with normal rats. Furthermore, levels of a-waves, b-waves and oscillatory potential amplitudes on ERGs in STZ rats were decreased compared with healthy animals. With use of shotgun proteomics, 391 proteins were identified in the retinas of normal rats and 541 proteins were found in the retinas of STZ rats. Of the 560 proteins identified in rat retinas, 372 $(66.4 \%)$ were present in both normal and STZ rats. Of these, $19(3.39 \%)$ were unique to normal rats and 169 (30.1\%) were unique to STZ rats. Gene Ontology analysis was performed on the candidate proteins that were differentially regulated in the retinas of STZ rats and focused on those classified as 'protein binding', which serve important roles in retinal neurodegeneration. The results revealed an excessive expression of retinol-binding protein 1 (RBP1) and a negative expression of rod outer segment membrane protein 1 (Rom-1) in the retinas of STZ rats. Therefore, retinal function may be decreased with STZ-induced injury, and expressions of Rom-1 and RBP1 may be altered in the retinas of STZ rats.
\end{abstract}

Correspondence to: Dr Noriaki Nagai, Faculty of Pharmacy, Kindai University, 3-4-1 Kowakae, Higashi-Osaka, Osaka 577-8502, Japan E-mail: nagai_n@phar.kindai.ac.jp

${ }^{*}$ Contributed equally

Abbreviations: ERGs, electroretinogram; GO, Gene Ontology; LC/MS, liquid chromatography/mass spectroscopy; NSAF, normalized spectral abundance factor; OP, oscillatory potential; RBP1, retinolbinding protein 1; Rom-1, rod outer segment membrane protein 1; SE, standard error; STZ rat, streptozotocin-induced diabetic rat

Key words: retinal degeneration, shotgun proteomics, streptozotocin-induced diabetic rat, rod outer segment membrane protein 1 , retinol-binding protein 1

\section{Introduction}

Ophthalmic functional disorders and blindness significantly affect quality of life due to the importance of vision in day-to-day activities. Diabetic retinopathy, glaucoma, age-related macular degeneration, and retinitis pigmentosa are diseases of the retina that can lead to blindness. The underlying mechanisms are of global interest, though it is difficult to prevent retinal dysfunction completely. Thus, it is important to elucidate how retinal stimulation leads to retinal dysfunction.

Animal models of retinopathy include the streptozotocin-induced diabetic rat (STZ rat), oxygen-induced retinopathy, and laser-induced choroidal neovascularization models (1-3). In particular, STZ rats serve as models of diabetic retinopathy. In a previous study, we showed that STZ rats have decreased retinal function using electroretinograms (ERGs) $(4,5)$. Moreover, STZ rats have altered visually evoked potentials or ERG measures even in the absence of observable retinopathy (6). Thus, STZ rats are adaptable as a model of acute retinal dysfunction. However, the differential retinal protein expression related to acute retinal dysfunction after STZ administration needs to be evaluated. A proteomic approach has been used for this purpose in diabetic retinopathy (7), with shotgun liquid chromatography (LC)/mass spectrometry (MS)-based global proteomic analysis considered particularly useful (8-10). We previously used this methodology to evaluate changes in protein expression in the lens and cornea of STZ rats and found decreased superoxide dismutase. This decrease contributed to the progression of diabetic cataracts and overexpression of lumican, leading to delayed corneal wound healing in diabetic keratopathy-affected corneas $(11,12)$.

In the present study, we used a shotgun LC/MS-based global proteomic approach in retinas from STZ rats to investigate factors relevant to and mechanisms underlying acute retinal dysfunction. We also identified proteins up- and downregulated in the retina and their association with retinal function.

\section{Materials and methods}

Materials. We purchased urea from GE Healthcare UK, Ltd. and thiourea and Triton X-100 from NACALAI TESQUE, Inc.. All other reagents and solvents were of analytical or HPLC grade.

Animals. Healthy male Wistar rats were provided by Kiwa Laboratory Animals Co., Ltd. The 6-week-old animals were 
injected with streptozotocin for 2 days $(100 \mathrm{mg} / \mathrm{kg} / \mathrm{day}$, i.p.) (13) and housed for 2 weeks. Sodium pentobarbital overdose (i.p.) was used to euthanize the rats, and the retinas were excised. All experiments were performed in compliance with regulations approved by the Ethics Committee of the Kindai University Faculty of Pharmacy (approval code KAPS-25-001, 1 April 2013). The rats were housed in a room at $25^{\circ} \mathrm{C}$ under a 12-h light-dark cycle (2-3 rats/cage). All rats had access to food and water ad libitum.

Assay of glucose and insulin levels. Blood (50 $\mu \mathrm{l})$ was sampled from the tail vein of each rat without anesthesia after the animal fasted for $12 \mathrm{~h}$ (10:00 a.m.). Plasma glucose level was measured using an Accutrend GCT (Roche Diagnostics $\mathrm{GmbH}$ ). Plasma insulin levels were assayed using an ELISA insulin kit (Morinaga Institute of Biological Science, Inc.) according to the manufacturer's protocol (14). The dynamic range of the ELISA Insulin kit is 0.1 to $6.4 \mathrm{ng} / \mathrm{ml}$.

ERG readings. ERG readings were recorded by PuREC (Mayo) at baseline and 2 weeks after streptozotocin injection. Rats were maintained in a completely dark room for $24 \mathrm{~h}$, after which they were anesthetized with isoflurane (concentration: $2.0 \mathrm{v} / \mathrm{v} \%$, flow rate: $1.0 \mathrm{l} / \mathrm{min}$ ). The pupils were dilated with $0.5 \%$ tropicamide and $0.5 \%$ phenylephrine (Santen). The golden-ring electrode, reference electrode, and neutral electrode (Mayo) were set at the right eye, tongue, and tail, respectively. A flash ERG was recorded in a dark room and a-wave, b-wave, and oscillatory potential (OP) amplitudes (OP1, OP2, and OP3) measured. The OPs were isolated by the band-pass filter and amplitudes measured using all frequencies $(0.3-500 \mathrm{~Hz})$.

Tryptic digestion of proteins extracted from the retinas of normal and STZ rats. Normal and STZ rats were euthanized by intraperitoneal injection of $150 \mathrm{mg} / \mathrm{kg}$ sodium pentobarbital. Retinas were removed from normal and STZ rats and homogenized in urea lysis buffer (7 M urea, $2 \mathrm{M}$ thiourea, $5 \%$ CHAPS, and 1\% Triton X-100). We measured protein concentrations using a Bio-Rad Protein Assay kit (Bio-Rad Laboratories, Inc.), followed by gel-free trypsin treatment in accordance with the previously published protocol (15). Briefly, $10 \mu \mathrm{g}$ of protein extract from each sample was reduced at $37^{\circ} \mathrm{C}$ for $30 \mathrm{~min}$ by the addition of $45 \mathrm{mM}$ dithiothreitol and $20 \mathrm{mM}$ Tris (2-carboxyethyl) phosphine in $50 \mathrm{mM}$ ammonium bicarbonate buffer. The proteins were then alkylated with $100 \mathrm{mM}$ iodoacetamide in $50 \mathrm{mM}$ ammonium bicarbonate buffer at $37^{\circ} \mathrm{C}$ for $30 \mathrm{~min}$. After alkylation, the samples were digested at $37^{\circ} \mathrm{C}$ for $24 \mathrm{~h}$ using MS-grade trypsin gold (Promega Corporation) at a trypsin/protein ratio of 1:100 (w:w). Finally, the digests were purified using PepClean C-18 Spin Columns (Thermo Fisher Scientific, Inc.) following the manufacturer's protocol.

LC-MS/MS identification of proteins. Peptide samples $(\sim 2 \mu \mathrm{g})$ were injected into a peptide L-trap column (Chemicals Evaluation and Research Institute, Tokyo, Japan) with an HTC PAL autosampler (CTC Analytics, Zwingen, Switzerland). They were further separated through a Paradigm MS4 (AMR Inc.) with a reverse-phase C18-column (L-column, 3- $\mu \mathrm{m}$-diameter gel particles, $120 \AA$ pore size, $0.2 \times 150 \mathrm{~mm}$; Chemicals Evaluation and Research Institute, Tokyo, Japan). The column flow rate was $1 \mu \mathrm{l} / \mathrm{min}$. The mobile phase consisted of $0.1 \%$ formic acid in water (solution A) and acetonitrile (solution B), with a concentration gradient of $5 \%$ solution B to $40 \%$ solution B over $120 \mathrm{~min}$. Gradient-eluted peptides were introduced into the mass spectrometer through the nanoelectrospray ionization (NSI) interface, which had a separation column outlet directly connected to the NSI needle. We analyzed the peptides using an LTQ ion-trap mass spectrometer (Thermo Fisher Scientific, Inc.) with no sheath or auxiliary gas. The MS scan sequence was full-scan MS in normal/centroid mode and sequential MS/MS in normal/centroid mode. The positive ion mass spectra were acquired in a data-dependent manner, with MS/MS fragmentation performed on the two most intense peaks of every full MS scan using an isolation width of $\mathrm{m} / \mathrm{z}$ 1.0 and a collisional activation amplitude of $35 \%$ in the $\mathrm{m} / \mathrm{z}$ range of 300 to 2,000. All MS/MS spectral data were searched against the SwissProt Rattus database using Mascot version 2.4.01 (Matrix Science). The search criteria were trypsin, with the following allowances: $\leq 2$ missed cleavage peptides; mass tolerance, $\pm 2.0 \mathrm{Da}$; MS/MS tolerance, $\pm 0.8 \mathrm{Da}$; cysteine carbamidomethylation for fixed modification; and methionine oxidation modifications for variable modification.

Semiquantitative analysis of identified proteins. The fold change in expression was calculated as the $\log 2$ of the ratio of protein abundances (Rsc) evaluated by spectral counting (16). The Rsc was calculated using Equation 1:

$$
R s c=\log 2\left[\left(n_{s}+f\right) /\left(n_{n}+f\right)\right]+\log 2\left[\left(t_{n}-n_{n}+f\right) /\left(t_{s}-n_{s}+f\right)\right]
$$

Here, $n_{n}$ and $n_{s}$ are spectral counts for the proteins in the retinas of normal and STZ rats, respectively, $t_{n}$ and $t_{s}$ are the total numbers of spectra for all proteins in the two samples, and $f$ is a correction factor set to 1.25 .

For comparison, we calculated the relative amount of proteins identified using the normalized spectral abundance factor (NSAF) (17). The NSAF was calculated using Equation 2:

$$
\mathrm{NSAF}=\left(\mathrm{SpC}_{\mathrm{n}} / \mathrm{L}_{\mathrm{n}}\right) / \mathrm{SUM}\left(\mathrm{SpC}_{\mathrm{n}} / \mathrm{L}_{\mathrm{n}}\right)
$$

Here, $\mathrm{SpC}_{\mathrm{n}}$ is the spectral count for the protein in the retinas of normal or STZ rats, and Ln is the length of the protein in the retinas of normal or STZ animals. Differentially expressed proteins were selected when the Rsc was $>1$ or $<-1$, which correspond to fold changes of $>2$ or $<0.5$, respectively.

Bioinformatics. We also investigated the functions of proteins with significantly altered expression in diabetes mellitus. Their sequences were assigned to Gene Ontology (GO) molecular function, GO cellular component, GO biological process, and Kyoto Encyclopedia of Genes and Genomes signaling pathway terms to examine their functional annotations in the Database for Annotation, Visualization, and Integrated Discovery (DAVID) version 6.8 (http://david.abcc.ncifcrf.gov/home.jsp) (18-20).

Statistical analysis. Statistical analysis was performed using JMP 5.1 software (SAS Institute, Inc.). All data are presented 

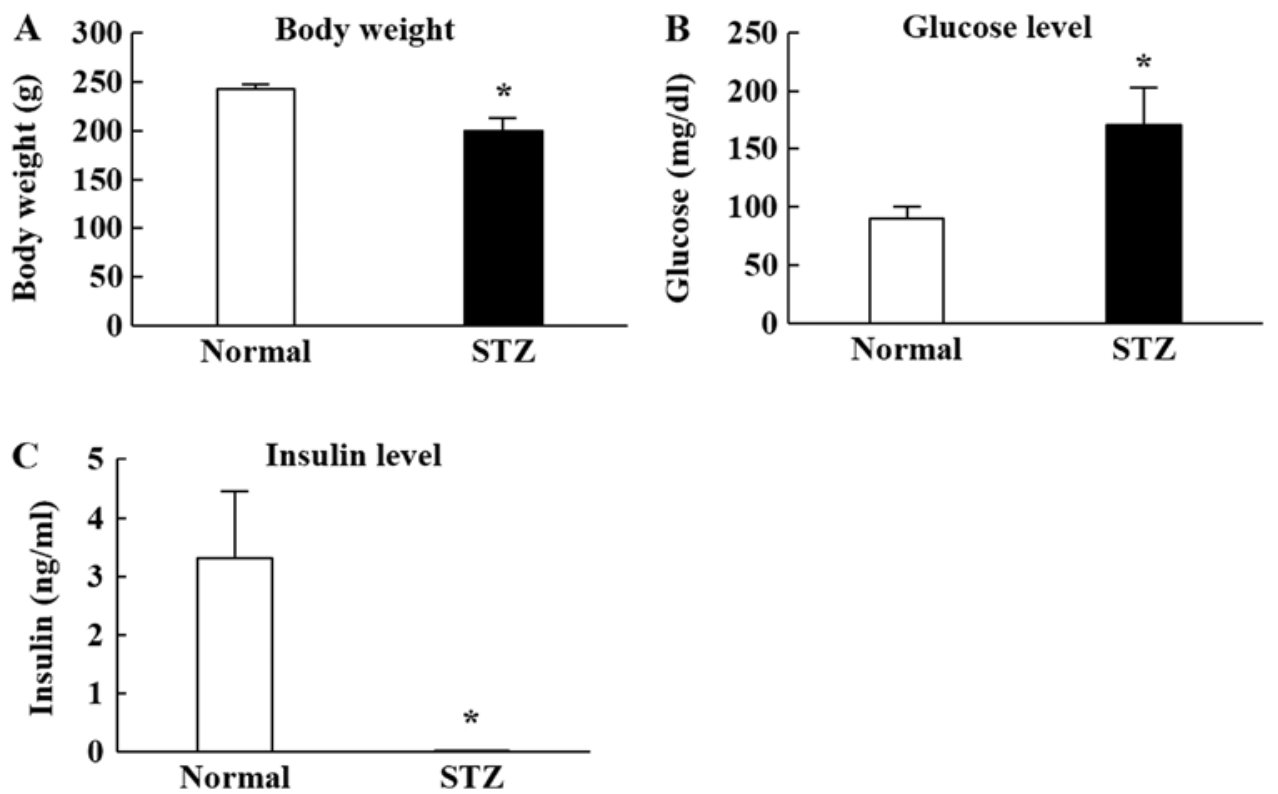

Figure 1. Effects of STZ administration in rats. (A) Body weight, (B) plasma glucose and (C) plasma insulin levels in normal and STZ rats were determined. Data are presented as the mean \pm standatd error $(n=3) .{ }^{*} \mathrm{P}<0.05$ vs. normal rats. STZ, streptozotocin.

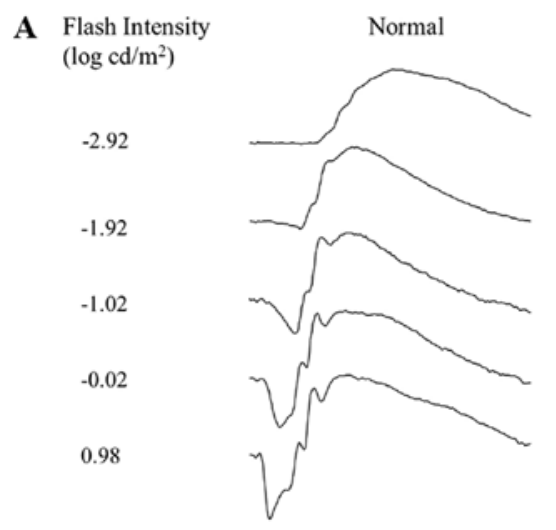

STZ
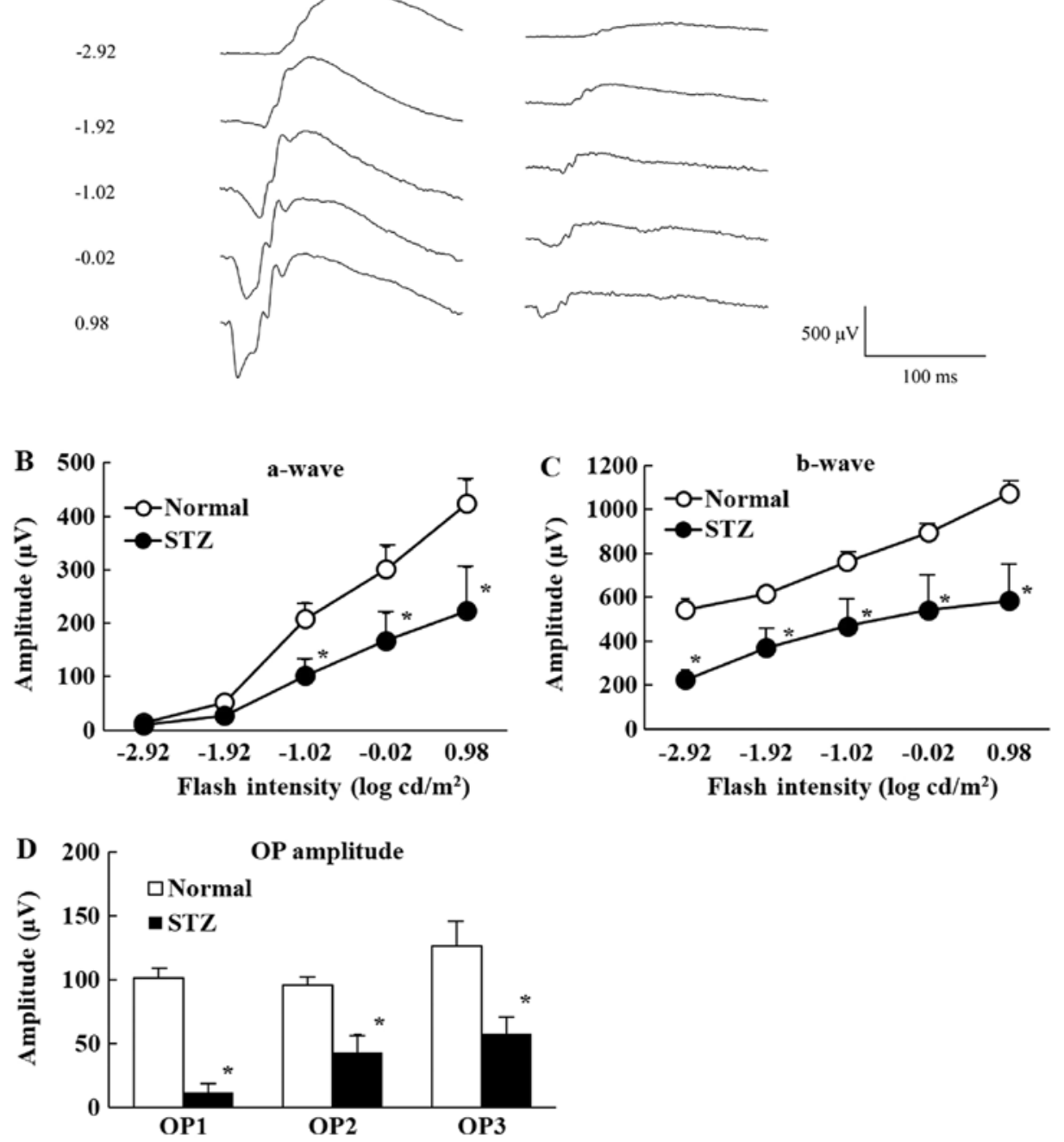

Figure 2. Changes in ERG typical traces of normal and STZ rats. (A) Typical traces of ERG, (B) a-waves, (C) b-waves, and (D) OP amplitudes in normal (open symbols) and STZ rats (closed symbols and columns). Data are presented as the mean \pm standard error $(\mathrm{n}=3)$. ${ }^{*} \mathrm{P}<0.05 \mathrm{vs}$. normal rats. ERG, electroretinogram; OP, oscillatory potential; STZ, streptozotocin. 
A

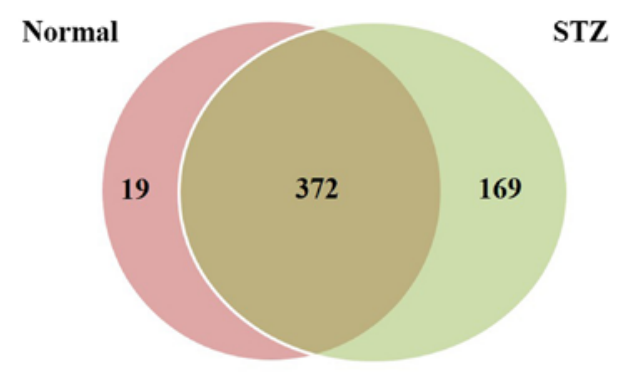

\section{B}

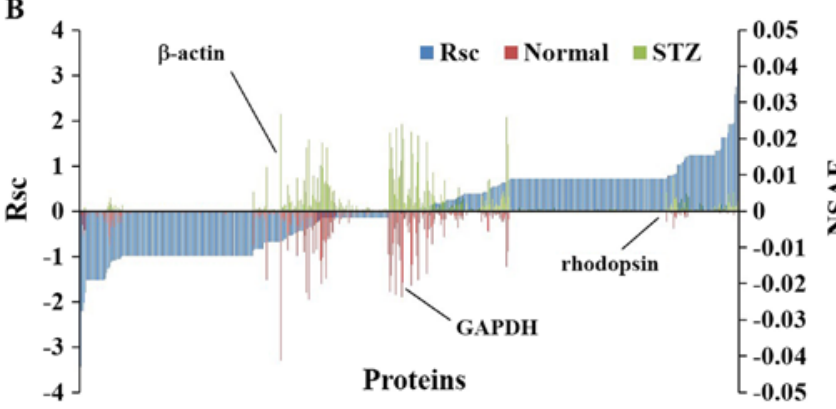

Figure 3. Identification and semiquantitative comparisons of differentially expressed proteins in the retinas of normal and STZ rats. (A) Venn diagram of proteins identified in the retinas of normal and STZ rats. (B) Semiquantitative comparison of proteins differentially expressed in the retinas of STZ rats. For each protein identified, Rsc and NSAF values were calculated to compare protein expression levels between the retinas of normal and STZ rats. STZ, streptozotocin; Rsc, ratio of protein abundances; NSAF, normalized spectral abundance factor.

as means \pm standard error of (SE). We applied the Student's $\mathrm{t}$-test and set the significance level at $\mathrm{P}<0.05$.

\section{Results}

Measurement of body weight, glucose, and insulin levels in STZ rats. Fig. 1 shows the changes in body weight, plasma glucose, and insulin levels in STZ rats, which were all significantly lower than in normal rats (Fig. 1A and C). The body weight of STZ rats was $80 \%$ that of normal rats. The plasma insulin level was below the detection sensitivity limit of the high sensitivity ELISA Insulin Kit. Furthermore, plasma glucose in STZ rats was markedly increased compared to normal rats (Fig. 1B).

Changes in retinal function in STZ rats. Fig. 2 shows the retinal function of normal and STZ rats on the ERGs. The a-waves reflect the function of photoreceptors, b-waves reflect bipolar cell and Müller cell function, and OP amplitudes are dependent on the hemodynamics in the central retinal artery. Retinal dysfunction was evident 2 weeks after streptozotocin injection with the a-wave, b-wave, and OP amplitudes lower in STZ rats than normal rats.

Changes in protein expression in the retinas of STZ rats. We identified 391 proteins in the retinas of normal rats and 541 proteins in the retinas of STZ rats (Fig. 3A). A total of 560 proteins were identified in the rat retina, including 372 (66.4\%) present in both normal and STZ animals, 19 (3.39\%) unique to normal rats, and 169 (30.1\%) unique to STZ rats (Fig. 3A). We also evaluated the proteins expressed in rat
Table I. Gene Ontology analysis of identified proteins in the molecular function category.

\begin{tabular}{lc}
\hline Molecular function category & Relative abundance $(\%)$ \\
\hline Protein binding & 29.5 \\
Poly(A) RNA binding & 13.6 \\
Structural molecule activity & 13.6 \\
Identical protein binding & 11.4 \\
Ubiquitin protein ligase binding & 10.2 \\
ATPase activity & 7.95 \\
RNA binding & 7.95 \\
GTP binding & 6.81 \\
Signal transducer activity & 5.68 \\
Cytoskeletal protein binding & 4.54 \\
Hydrogen ion transmembrane & 4.54 \\
transporter activity & \\
Ion channel binding & 4.54 \\
Unfolded protein binding & 4.54 \\
Retinal binding & 2.27 \\
\hline
\end{tabular}

retinas using a label-free semiquantitative method based on spectral counting. Fig. 3B shows the Rsc values for the proteins identified in the normal and STZ rats. A positive Rsc indicated increased expression in the diabetic rat retina, and a negative value indicated reduced expression. Furthermore, the NSAF value was calculated for each protein identified in the normal and STZ rats. Proteins with an Rsc $>1$ or $<-1$ were considered candidate proteins exhibiting differential regulation with diabetic retinopathy. The expression levels of housekeeping proteins, such as $\beta$-actin and glyceraldehyde-3-phosphate dehydrogenase, did not change in the retinas of STZ rats (Fig. 3B).

We performed GO analysis of the candidate proteins regulated in the retinas of STZ rats. For this purpose, we searched for GO terms related to 'molecular function' (Table I), 'cellular component' (Table II), 'biological processes' (Table III), and 'Pathway' (Table IV) in DAVID. Our focus was on the nine proteins classified as 'protein binding', which play important roles in retinal neurodegeneration in the GO 'molecular function' component (Table V). Among these nine proteins, we homed in on the effect of enhanced expression of retinol-binding protein 1 (RBP1) and negative expression of rod outer segment membrane protein 1 (Rom-1) in the retinas of STZ rats because both proteins are key factors in acute retinal degeneration.

\section{Discussion}

In this study, we investigated the relationship between retinal dysfunction and retinal protein expression using shotgun proteomics in a model of diabetic retinopathy. Selection of an appropriate model animal is essential for investigating this relationship. Streptozotocin exposure damages pancreatic $\beta$-cells in rats, leading to deficient insulin secretion $(21,22)$. In our previous work, we used STZ rats as a model of acute diabetic retinopathy (6); here, we examined glucose and insulin levels 
Table II. Gene Ontology analysis of identified proteins in the cellular component category.

\begin{tabular}{|c|c|}
\hline Cellular component category & Relative abundance (\%) \\
\hline Extracellular exosome & 29.5 \\
\hline Cytoplasm & 13.6 \\
\hline Nucleus & 13.6 \\
\hline Membrane & 11.4 \\
\hline Cytosol & 10.2 \\
\hline Extracellular space & 17.0 \\
\hline Mitochondrion & 15.9 \\
\hline Myelin sheath & 14.8 \\
\hline Golgi apparatus & 12.5 \\
\hline Perinuclear region of cytoplasm & 12.5 \\
\hline Neuron projection & 11.4 \\
\hline Protein complex & 9.09 \\
\hline Cell body & 7.95 \\
\hline Focal adhesion & 7.95 \\
\hline Synapse & 7.95 \\
\hline Terminal bouton & 7.95 \\
\hline Extracellular matrix & 6.81 \\
\hline $\begin{array}{l}\text { Intracellular ribonucleoprotein } \\
\text { complex }\end{array}$ & 6.81 \\
\hline Postsynaptic density & 6.81 \\
\hline Cytoplasmic vesicle & 5.68 \\
\hline Intermediate filament & 5.68 \\
\hline Synaptic vesicle & 5.68 \\
\hline Blood microparticle & 4.54 \\
\hline Dendritic spine & 4.54 \\
\hline Melanosome & 4.54 \\
\hline MPT-ATP SC, coupling factor F (o) & 4.54 \\
\hline MPT-ATP SC & 4.54 \\
\hline Perikaryon & 4.54 \\
\hline Clathrin-coated vesicle & 3.41 \\
\hline Intermediate filament cytoskeleton & 3.41 \\
\hline Photoreceptor outer segment & 3.41 \\
\hline $\begin{array}{l}\text { Photoreceptor outer segment } \\
\text { membrane }\end{array}$ & 2.27 \\
\hline
\end{tabular}

MPT-ATP SC, Mitochondrial proton-transporting ATP synthase complex.

in the plasma of STZ rats. Plasma glucose levels were significantly higher in STZ rats than in normal rats. Furthermore, we could not detect plasma insulin in STZ rats, which had significantly decreased body weight compared to normal rats (Fig. 1). These results show that STZ rats developed diabetes mellitus with hyperglycemia and hypoinsulinemia.

Diabetic retinopathy is a common complication associated with diabetes mellitus (23-25). This disease is characterized by progressive alteration of the retinal microvasculature derived from hyperglycemia (23), which leads to capillary closure and areas of non-perfusion. This phenomenon causes retinal hypoxia and pathological neovascularization, which leads to vision loss.
Table III. Gene Ontology analysis of identified proteins in the biological process category.

\begin{tabular}{|c|c|}
\hline Biological process category & Relative abundance (\%) \\
\hline Response to drug & 10.2 \\
\hline $\begin{array}{l}\text { Negative regulation of apoptotic } \\
\text { process }\end{array}$ & 9.10 \\
\hline Aging & 6.82 \\
\hline Protein transport & 6.82 \\
\hline Vesicle-mediated transport & 6.82 \\
\hline ATP metabolic process & 5.68 \\
\hline $\begin{array}{l}\text { ATP synthesis coupled protein } \\
\text { transport }\end{array}$ & 5.68 \\
\hline Endocytosis & 4.54 \\
\hline $\begin{array}{l}\text { ATP hydrolysis coupled proton } \\
\text { transport }\end{array}$ & 3.41 \\
\hline Chromatin silencing & 3.41 \\
\hline Epidermis development & 3.41 \\
\hline Intermediate filament organization & 3.41 \\
\hline Regulation of endocytosis & 3.41 \\
\hline Response to axon injury & 3.41 \\
\hline Retina homeostasis & 3.41 \\
\hline RVMT, Golgi to ER & 3.41 \\
\hline Substantia nigra development & 3.41 \\
\hline Toxin transport & 3.41 \\
\hline $\begin{array}{l}\text { Cellular response to Thyroid } \\
\text { stimulating hormone }\end{array}$ & 2.27 \\
\hline Mucus secretion & 2.27 \\
\hline $\begin{array}{l}\text { Negative regulation of intracellular } \\
\text { transport }\end{array}$ & 2.27 \\
\hline $\begin{array}{l}\text { Regulation of histamine secretion } \\
\text { by mast cell }\end{array}$ & 2.27 \\
\hline
\end{tabular}

RVMT, Retrograde veside-mediated transport.

Table IV. Gene Ontology analysis of identified proteins in the pathway category.

\begin{tabular}{lc}
\hline Pathway category & Relative abundance (\%) \\
\hline Oxidative phosphorylation & 10.2 \\
Huntington's disease & 9.10 \\
Endocytosis & 6.82 \\
Alcoholism & 5.68 \\
Alzheimer's disease & 5.68 \\
Parkinson's disease & 5.68 \\
Synaptic vesicle cycle & 5.68 \\
Glutamatergic synapse & 4.54 \\
Collecting duct acid secretion & 3.41
\end{tabular}

Next, we used ERGs to investigate changes in retinal function after streptozotocin injection, measuring a-wave, 
Table V. Proteins categorized as 'protein binding' in Gene ontology analysis.

\begin{tabular}{|c|c|c|c|c|c|c|}
\hline \multirow[b]{2}{*}{ ID } & & & \multirow[b]{2}{*}{$\begin{array}{c}\text { Number } \\
\text { of amino } \\
\text { acids }\end{array}$} & \multicolumn{3}{|c|}{ Spectral counting } \\
\hline & & Accession number and description & & Normal & STZ & $\begin{array}{l}\text { Fold } \\
\text { change } \\
\text { (Rsc) }\end{array}$ \\
\hline ROM1_RAT & Q5PPM7 & Rod outer segment membrane protein 1 & 351 & 4 & 0 & -2.212260 \\
\hline VAMP3_RAT & P63025 & Vesicle-associated membrane protein 3 & 103 & 7 & 1 & -2.017270 \\
\hline PUF60_RAT & Q9WV25 & Poly(U)-binding-splicing factor PUF60 & 564 & 2 & 0 & -1.519500 \\
\hline TBKB1_RAT & Q6DG50 & TANK-binding kinase 1-binding protein 1 & 613 & 2 & 0 & -1.519500 \\
\hline GNA12_RAT & Q63210 & $\begin{array}{l}\text { Guanine nucleotide-binding protein } \\
\text { subunit alpha- } 12\end{array}$ & 379 & 2 & 0 & -1.519500 \\
\hline GBB4_RAT & $\mathrm{O} 35353$ & $\begin{array}{l}\text { Guanine nucleotide-binding protein } \\
\text { subunit beta- } 4\end{array}$ & 340 & 3 & 9 & 1.132274 \\
\hline GBB3_RAT & P52287 & $\begin{array}{l}\text { Guanine nucleotide-binding protein } \\
\mathrm{G}(\mathrm{I}) / \mathrm{G}(\mathrm{S}) / \mathrm{G}(\mathrm{T}) \text { subunit beta-3 }\end{array}$ & 340 & 0 & 2 & 1.239212 \\
\hline DDB1_RAT & Q9ESW0 & DNA damage-binding protein 1 & 1,140 & 0 & 2 & 1.239212 \\
\hline RET1_RA & P02696 & Retinol-binding protein 1 & 135 & 1 & 7 & 1.736735 \\
\hline
\end{tabular}

b-wave, and OP amplitude (Fig. 2). Retinal neuron loss has been reported early in disease progression in STZ rats, and this neuronal dysfunction was reflected in alterations in the ERG findings (26-28). After streptozotocin injection, the a-waves and b-waves of STZ rats decreased. OP amplitude, which indicates the amplitude of the small wave between the a-wave and b-wave peak, was also significantly lower in STZ rats than normal rats. These reductions in a-wave, b-wave, and OP amplitude have also been observed in human diabetic retinopathy $(29,30)$. Moreover, our previous study showed that, with increased thickening of the retinal nerve cell layer, in particular, the gap between the ganglion cell layer and inner granular layer was extended (6). These results suggest that the rat retina is injured by streptozotocin injection, and that the localized factor and cell layer distance are related to retinal dysfunction.

Next, we applied LC/MS-based proteomics analysis to elucidate factors and mechanisms of acute retinal dysfunction in STZ rats. Although a quantitative value obtained using spectral counting may not be accurate, it reflects differences in expression and has been used in previous studies investigating novel diagnostic biomarkers and biological mechanisms (11,12,31-35). A total of 88 proteins had $>2$-fold change in expression in the retinas of STZ rats, and we examined their roles in an analysis against four GO terms. For this purpose, we focused on changes in the expression of proteins classified into the 'protein binding' category in the 'molecular function' term because the relative abundance of this category was highest among the 'molecular function' terms. Proteins that are categorized into 'protein binding' have the potential to interact with other proteins. Thus, these molecules may play an important role in the decreased ERG measures in STZ rats given the increased thickening of the retinal nerve cell layer in these animals (6). The nine proteins were categorized, and those showing the highest and lowest Rsc values were RBP1 and Rom-1, respectively. Both proteins have been reported to be involved in the retinoid cycle.
Visual pigment (11-cis-retinal + opsin protein) is necessary for functioning photo receptors in the retina, and the visual pigments are regenerated in the rod outer segment and retinal pigment epithelium (retinoid cycle). In the retinoid cycle, the visual pigment is isomerized to all-trans-retinal by a light signal in the rod outer segment disk. The isomerized all-trans-retinal is produced by the reduction to all-trans-retinol via $\mathrm{ABC}$ cassette transporter and all-trans-retinol dehydrogenase, and is released into the gap between the photoreceptor outer segment and retinal pigment epithelium. The released all-trans-retinol is taken into the retinal pigment epithelium by $\mathrm{RBP} 1$, regenerated into 11-cis-retinal, and reversed into the photoreceptor outer segments via RBP1 (36-39). Low RBP1 decreases the transport of 11-cis-retinal and all-trans-retinol to the rod outer segment and retinal pigment epithelium, respectively. Chen et al reported that RBP1 not only transports 11-cis-retinal and all-trans-retinol, but also efficiently releases all-trans-retinol from rod photoreceptors in a concentration-dependent manner (40). These effects prevent the production of lipofuscin precursor, which is a factor in retinal dysfunction (40). In this study, RBP1 levels were significantly higher in the retinas of STZ rats than normal rats. These findings suggest that the expression of RBP1 may be increased by homeostatic mechanisms against the suppression of lipofuscin production.

Rom-1 is a retina-specific integral membrane protein localized to the rod outer segment disk rim $(41,42)$. Rom- 1 has been reported to be involved in the stabilization and compaction of outer segment disks and rim maintenance, which is essential for morphogenesis in the rod outer segment disk (43). A previous study also showed that Rom-1 knockout mice have recessive photoreceptor degeneration (44). In the present study, Rom-1 levels were lower in the retinas of STZ rats than normal rats. As the results of semi-quantitative analysis based on spectral counts highly correlate with the results of quantification by Western blot in previous studies $(12,45,46)$, the expression of 
RBP1 and Rom-1 are considered to have changed. These results suggest that the decreased expression of Rom-1 is related to retinal dysfunction via the destabilization of morphogenesis in the rod outer segment disk. Further study is needed to investigate whether RBP1 and Rom-1 protein levels decreased in STZ rats via Western blotting and to elucidate the mechanism underlying changes in Rom-1 and RBP1 in acute retinopathy in STZ rats.

In conclusion, streptozotocin injury decreased retinal function in rats. In association with this functional loss, shotgun proteomics revealed altered expression of Rom-1 and RBP1, which play important roles in maintaining the retinoid cycle.

\section{Acknowledgements}

Not applicable.

\section{Funding}

No funding was received.

\section{Availability of data and materials}

All data generated or analyzed during this study are included in this published article.

\section{Authors' contributions}

HO, TY and NN performed the experiments and wrote the manuscript. TY and SD analyzed and interpreted the data. AT conceived and designed the current study. NN designed the experiments and gave final approval for the version of the manuscript to be published. All authors read and approved the final manuscript.

\section{Ethics approval and consent to participate}

All experiments were performed in compliance with the regulations approved by the Ethics Committee of the Kindai University Faculty of Pharmacy (Ethic Committee approval code, KAPS-25-001; Date of approval, April 1, 2013).

\section{Patient consent for publication}

Not applicable.

\section{Competing interests}

The authors declare that they have no competing interests.

\section{References}

1. Radenković M, Stojanović M and Prostan M: Experimental diabetes induced by alloxan and streptozotocin: The current state of the art. J Pharmacol Methods 78: 13-31, 2016.

2. Goyal SN, Reddy NM,Patil KR, Nakhate KT, Ojha S, Patil CR and Agrawal YO: Challenges and issues with streptozotocin-induced diabetes-A clinically relevant animal model to understand the diabetes pathogenesis and evaluate therapeutics. Chem Biol Interact 244: 49-63, 2016

3. Liu CH, Wang Z, Sun Y and Chen J: Animal models of ocular angiogenesis: From development to pathologies. FASEB J 31: 4665-4681, 2017.
4. Nagai N, Deguchi S, Otake H, Hiramatsu N and Yamamoto N: Therapeutic effect of cilostazol ophthalmic nanodispersions on retinal dysfunction in streptozotocin-induced diabetic rats. Int J Mol Sci 18: pii: E1971, 2017.

5. Deguchi S, Otake H, Nakazawa Y, Hiramatsu N, Yamamoto N and Nagai N: Ophthalmic formulation containing nilvadipine nanoparticles prevents retinal dysfunction in rats injected with streptozotocine. Int J Mol Sci 18: pii: E2720, 2017.

6. Hiramatsu N, Deguchi S, Yoshioka C, Otake H, Yamamoto N and Nagai N: Evaluation of retinal function in streptozotocin-induced diabetic rats by using the electroretinography and immunohistochemistry methods. Yakugaku Zasshi 137: 1169-1175, 2017 (In Japanese).

7. Gopalakrishnan V, Purushothaman P and Bhaskar A: Proteomic analysis of plasma proteins in diabetic retinopathy patients by two dimensional electrophoresis and MALDI-Tof-MS. J Diabetes Complications 29: 928-936, 2015.

8. Joseph R, Srivastava OP and Pfister RR: Differential epithelial and stromal protein profiles in keratoconus and normal human corneas. Exp Eye Res 92: 282-298, 2011.

9. Yamamoto T, Kudo M, Peng WX and Naito Z: Analysis of protein expression regulated by lumican in PANC-1 cells using shotgun proteomics. Oncol Rep 30: 1609-1621, 2013.

10. Meade ML, Shiyanov P and Schlager JJ: Enhanced detection method for corneal protein identification using shotgun proteomics. Proteome Sci 7: 23, 2009.

11. Nagai N, Yamamoto T, Mitamura K and Taga A: Proteomic profile of the lens in a streptozotocin-induced diabetic rat model using shotgun proteomics. Biomed Rep 7: 445-450, 2017.

12. Yammoto T, Otake H, Hiramatsu N, Yamamoto N, Taga A and Nagai N: A proteomic approach for understanding the mechanisms of delayed corneal wound healing in diabetic keratopathy using diabetic model rat. Int J Mol Sci 19: pii: E3635, 2018.

13. Ma DH, Lai JY, Yu ST, Liu JY, Yang U, Chen HC, Yeh LK, Ho YJ, Chang G, Wang SF, et al: Up-regulation of heat shock protein 70-1 (Hsp70-1) in human limbo-corneal epithelial cells cultivated on amniotic membrane: A proteomic study. J Cell Physiol 227: 2030-2039, 2012.

14. Nagai N, Ito $\mathrm{Y}$ and Sasaki H: Hyperglycemia enhances the production of amyloid $\beta 1-42$ in the lenses of otsuka long-evans tokushima fatty rats, a model of human type 2 diabetes. Invest Ophth Vis Sci 57: 1408-1417, 2016.

15. Bluemlein $\mathrm{K}$ and Ralser $\mathrm{M}$ : Monitoring protein expression in whole-cell extracts by targeted label- and standard-free LC-MS/MS. Nat Protoc 6: 859-869, 2011.

16. Old WM, Meyer-Arendt K, Aveline-Wolf L, Pierce KG, Mendoza A, Sevinsky JR, Resing KA and Ahn NG: Comparison of label-free methods for quantifying human proteins by shotgun proteomics. Mol cell Proteom 4: 1487-1502, 2005.

17. Zybailov B, Coleman MK, Florens L and Washburn MP: Correlation of relative adundance ratios derived from peptide ion chromatograms and spectrum counting for quantitative proteomic analysis using stable isotope labeling. Anal Chem 77: 6218-6224, 2005.

18. Dennis G Jr, Sherman BT, Hosack DA, Yang J, Gao W, Lane HC and Lempicki RA: DAVID: Database for annotation, visualization, and integrated discovery. Genome Biol 4: P3, 2003.

19. Huang da W, Sherman BT and Lempicki RA: Systematic and integrative analysis of large gene lists using DAVID bioinformatics resources. Nat Protoc 4: 44-57, 2009.

20. Huang da W, Sherman BT, Zheng X, Yang J, Inamichi T, Stephens R and Lempicki RA: Extracting biological meaning from large gene lists with DAVID. Curr Protoc Bioinformatics, Chapter 13: Unit 13.11, 2009.

21. Stephen Irudayaraj S, Sunil C, Duraipandiyan V and Ignacimuthu S: Antidiabetic and antioxidant activities of Toddalia asiatica (L.) Lam. Leaves in streptozotocin induced diabetic rats. J Ethnopharmacol 143: 515-523, 2012.

22. Nisha P and Mini S: Flavanoid rich ethyl acetate fraction of Musa paradisiaca inflorescence down-regulates the streptozotocin induced oxidative stress, hyperglycemia and mRNA levels of selected inflammatory genes in rats. J Funct Food 5: 1838-1847, 2013.

23. Miller JW, Adamis AP and Aiello LP: Vascular endothelial growth factor in ocular neovascularization and proliferative diabetic retinopathy. Diabetes Metab Rev 13: 37-50, 1997.

24. Cheung $\mathrm{N}$ and Wong TY: Diabetic retinopathy and systemic vascular complications. Prog Retin Eye Res 27: 161-176, 2008.

25. Cheung N, Mitchell P and Wong TY: Diabetic retinopathy. Lancet 376: 124-136, 2010. 
26. Barber AJ, Lieth E, Khin SA, Antonetti DA, Buchanan AG and Gardner TW: Neural apoptosis in the retina during experimental and human diabetes. J Clin Invest 102: 783-791, 1998.

27. Lecleire-Collet A, Audo I, Aout M, Girmens JF, Sofroni R, Erginary A, Gargasson JF, Mohand-Saïd S, Meas T, Guillausseau PJ, et al: Evaluation of retinal function and flicker light-induced retinal vascular response in normotensive patients with diabetes without retinopathy. Invest Ophthalmol Vis Sci 52 : 2861-2867, 2011

28. Hancock HA and Kraft TW: Oscillatory potential analysis and ERGs of normal and diabetic rats. Invest Ophthalmol Vis Sci 45: 1002-1008, 2004.

29. Layton CJ, Safa R and Osbrme NN: Oscillatory potentials and the b-wave: Partial masking and interdependence in dark adaptation and diabetes in the rat. Graefes Arch Clin Exp Ophthalmol 245: $1335-1345,2007$.

30. Samuels IS, Bell BA, Pereira A, Saxon J and Peachey NS: Early retinal pigment epithelium dysfunction is concomitant with hyperglycemia in mouse models of type 1 and type 2 diabetes. J Neurophysiol 113: 1085-1099, 2015.

31. Yamamoto T, Kudo M, Peng WX and Naito Z: Analysis of protein expression regulated by lumican in PANCc-1 cells using shotgun proteomics. Oncol Rep 30: 1609-1621, 2013.

32. Takaya A, Peng WX, Ishino K, Kudo M, Yamamoto T, Wada R, Takeshita $\mathrm{T}$ and Naito Z: Cystatin B as a potential diagnostic biomarker in ovarian clear cell carcinoma. Int J Oncol 46 : 1573-1581, 2015.

33. Kanzaki A, Kudo M, Ansai S, Peng WX, Ishino K, Yamamoto T, Wada R, Fujii T, Teduka K, Kawahara K, et al: Insulin-like growth factor 2 mRNA-binding protein-3 as a marker for distinguishing between cutaneous squamous cell carcinoma and keratoacanthoma. Int J Oncol 48: 1007-1015, 2016.

34. Yamamoto T, Kudo M, Peng WX, Takata H, Takakura H, Teduka K, Fujii T, Mitamura K, Taga A, Uchida E and Naito Z: Identification of aldolase $\mathrm{A}$ as a potential diagnostic biomarker for colorectal cancer based on proteomic analysis using formalin-fixed paraffin-embedded tissue. Tumor Biol 37: 13595-13606, 2016.

35. Takata H, Kudo M, Yamamoto T, Ueda J, Ishino K, Peng WX, Wada R, Taniai N, Yoshida H, Uchida E and Naito Z: Increased expression of PDIA3 and its association with cancer cell proliferation and poor prognosis in hepatocellular carcinoma. Oncol Lett 12: 4896-4904, 2016.

36. Saari JC: Biochemistry of visual pigment regeneration: The Friedenwald lecture. Investig Ophthalmol Vis Sci 41: 337-348, 2000.
37. Maeda A, Golczak M, Chen Y, Okano K, Kohno H, Shiose S, Ishikawa K, Harte W, Palczewska G, Maeda T and Palczewski K: Primary amines protect against retinal degeneration in mouse models of retinopathies. Nat Chem Biol 8: 170-178, 2011.

38. Lai Y, Wiggert B, Liu Y and Chader G: Interphotoreceptor retinol-binding proteins: Possible transport vehicles between compartments of the retina. Nature 26: 848-849, 1982.

39. Lin ZS, Fong S and Bridges CD: Retinoids bound to interstitial retinol-binding protein during light and dark-adaptation. Vision Res 29: 1699-1709, 1989.

40. Chen C, Adler L IV, Goletz P, Gonzalez-Femandez F, Thompson DA amd Koutalos Y: Interphotoreceptor retinoid-binding protein removes all-trans-retinol and retinal from rod outer segments, preventing lipofscin precursor formation. J Biol Chem 292: 19356-19365, 2017.

41. Bascom RA, Manara S, Collins L, Molday RS, Kalnins VI and Mclnnes RR: Cloning of the cDNA for a novel photoreceptor membrane protein (rom-1) identifies a disk rim protein family implicated in human retinopathies. Neuron 8: 1171-1184, 1992.

42. Bascom RA, Liu L, Humphries P, Fishman GA, Murray JC and Mclnnes RR: Polymorphisms and rare sequence variants at the ROM1 locus. Hum Mol Genet 2: 1975-1977, 1993.

43. Loewen CJ and Molday RS: Disulfide-mediated oligomerization of Peripherin/Rds and Rom-1 in photoreceptor disk membranes. Implications for photoreceptor outer segment morphogenesis and degeneration. J Biol Chem 275: 5370-5378, 2000.

44. Clarke G, Goldberg AF, Vidgen D, Collins L, Ploder L, Schwarz L, Molday LL, Rossant J, Szél A, Molday RS, et al: Rom-1 is required for rod photoreceptor viability and the regulation of disk morphogenesis. Nat Genet 25: 67-73, 2000.

45. Yamamoto T, Nishita T and Taga A: Dark-colored maple syrup treatment induces $\mathrm{S}$-phase cell cycle arrest via reduced proliferating cell nuclear antigen expression in colorectal cancer cells. Oncol Lett 17: 2713-2720, 2019.

46. Yamamoto T, Nakanishi S, Mitamura K and Taga A: Collagen peptides from soft-shelled turtle induce calpain-1 expression and regulate inflammatory cytokine expression in HaCaT human skin keratinocytes. Int J Mol Med 42: 1168-1180, 2018. 